\title{
EphA1 receptor silencing by small interfering RNA has antiangiogenic and antitumor efficacy in hepatocellular carcinoma
}

\author{
GANG CHEN $^{1}$, YI WANG ${ }^{2}$, MENGTAO ZHOU ${ }^{1}$, HONGQI SHI ${ }^{1}$, \\ ZHENGPING YU ${ }^{1}$, YEFAN ZHU ${ }^{1}$ and FUXIANG YU ${ }^{1}$ \\ ${ }^{1}$ Department of Hepatobiliary Surgery, The First Affiliated Hospital, Wenzhou Medical College, Wenzhou; \\ ${ }^{2}$ Environmental and Public Health School of Wenzhou Medical College, Wenzhou, P.R. China
}

Received September 3, 2009; Accepted October 22, 2009

DOI: $10.3892 /$ or_00000670

\begin{abstract}
The Eph family of receptor tyrosine kinases has emerged as one of the pivotal regulators of tumor angiogenesis. EphA1, the first identified member of the Eph receptor family, has been found to be overexpressed in several types of human tumors. A recent report indicated that EphA1 was overexpressed in hepatocellular carcinoma (HCC) and that elevated expression of EphA1 can promote proliferation of HCC cells through stimulation by exogenous Ephrin-A1. To investigate the role of EphA1 in angiogenesis and progression of HCC, we down-regulated EphA1 by RNA interference (RNAi) technology, in an HCC-derived cell line with a high level of EphA1 expression. We established a stable knockdown clone named SiEphA1/Huh-7. The knockdown resulted in decreased proliferation of Huh-7 cells, as well as decreased motility and invasion capability in vitro. siRNA-based EphA1 knockdown also downregulated the expression of vascular endothelial growth factor (VEGF) and matrix metalloproteinase (MMP)-2 and -9. Interestingly, the suppression of EphA1 expression in Huh-7 cells reduced their outgrowth when inoculated in the subcutaneous space in the flank of nude mice, presumably through angiogenesis inhibition since microvessel density was found to be inhibited.
\end{abstract}

\section{Introduction}

Hepatocellular carcinoma (HCC) is the fifth most common tumor worldwide and the third cause of cancer-related deaths, with more than half a million new cases each year (1). The

Correspondence to: Dr Gang Chen, Department of Hepatobiliary Surgery, The First Affiliated Hospital, Wenzhou Medical College, 2 Fuxue Road, Wenzhou 325000, P.R. China

E-mail: cg_2188@hotmail.com

Key words: EphA1, hepatocellular carcinoma, angiogenesis, siRNA poor prognosis is due to the high invasion and metastatic ability. Angiogenesis is known to play a vital role in tumor growth, invasion, and metastasis (2-4). Therefore, understanding the molecular mechanisms that regulate angiogenesis in hepatocellular carcinoma (HCC) may provide novel targets for cancer treatment. Endothelial cell receptor tyrosine kinases (RTK) have been recognized as critical mediators of angiogenesis. Among these are the vascular endothelial growth factor (VEGF) receptor, Tie, and Eph RTKs (5). The functions of both VEGF/VEGF receptor and angiopoietins/ Tie receptor families in vascular development and angiogenesis are well studied. The Eph receptor tyrosine kinase family, however, represents a new class of RTK, and their role in carcino-genesis and tumor angiogenesis is only beginning to emerge.

The role of the Eph family of receptors are well studied initially in the nervous system, especially in patterning the developing hindbrain rhombomeres, axon pathfinding, and guiding neural crest cell migration, as well as in biological processes during embryogenesis (6). Their function in carcinogenesis and tumor angiogenesis is receiving increasing attention. Overexpression of Eph receptors and Ephrins have been found in a variety of cancers including breast (7), prostate (8), lung (9), tongue (10), colon (11), gastric (12), esophageal tumors (13), as well as in melanoma (14), cervical (15) and ovarian (16) cancer and malignant mesothelioma (17). At the same time, antitumor and antiangiogenesis gene therapy targeted to the Eph family have shown great potential. Blockade of EphA2 activity using soluble EphA2-Fc can inhibited tumor angiogenesis and progression of ASPC-1 human pancreatic carcinoma xenografts, and restrained growth and metastasis of orthotopic human pancreatic ductal adenocarcinoma (18). Soluble EphA2-Fc or EphA3-Fc treatment of 4T1 tumors transplanted into syngeneic Balb/c mice resulted in decreased tumor volume and microvascular density within the tumor (19). Small interfering RNA-mediated ephrin-A1 knockdown in metastatic mammary tumor cells significantly reduced tumor-induced endothelial cell migration in vitro and microvascular density in vivo (20).

EphA1, as the first Eph receptor identified, was found expressed in erythropoeitin producing hepatoma cells (Eph) (21). Overexpression of EphA1 has been described in prostate 
cancer (22), gastric cancers (23) and a subset of colon, lung, liver and mammary carcinomas $(24,25)$. Overexpression of EphA1 in $\mathrm{NIH}_{3} \mathrm{~T}_{3}$ cells led to formation of foci in soft agar and promoted tumor formation in nude mice (26). Thus, EphA1 can be regarded as a classical oncogene (27). Although there have been a few studies on EphA1 in hepatocellular carcinoma, the concrete roles of EphA1 in carcinogenesis and angiogenesis of $\mathrm{HCC}$ have not been reported yet. A recent study showed that EphA1 was overexpressed not only in hepatocellular carcinoma cell lines, and in human tumor specimens, and elevated expression of EphA1 by exogenous EphrinA1 can promote proliferation of tumor cells (25). In order to validate the suitability of EphA1 as a target for gene therapy and to explore the roles and mechanisms of EphA1 in the progression of HCC, we used RNAi technology to knock down the expression of EphA1 in Huh-7 cells. The results obtained confirm that the proliferative, migratory and invasive capabilities of HCC cells can be affected by siRNA targeting EphA1. Our results further show that blockade of EphA1 expression can significantly reduce HCC tumor growth and tumor microvessel density in nude mice. We also found that EphA1 suppression is associated with downregulation of VEGF, but not Ang-2. In addition, the expression of matrix metalloproteinase-2 (MMP-2) and matrix metalloproteinase-9 (MMP-9) was found to be down-regulated in EphA1 suppressed Huh-7 cells. These changes may represent a mechanism for the EphA1-dependent angiogenesis and invasiveness we observed. The current results indicate that EphA1 mediates progression and angiogenesis of HCC, and suggest that gene therapy targeted to EphA1 can be used as a promising means for the treatment of HCC.

\section{Materials and methods}

Cell culture and animals. Human hepatocellular carcinoma cell line, Huh-7 was obtained from the Institute of Biochemistry and Cell Biology, Chinese Academy of Sciences, was grown in RPMI-1640 medium with $10 \%$ fetal calf serum (FCS). Male, 6-8-week old, athymic mice (BALB/c nu/nu) were purchased Animal Experimental Center of Slaccas (Shanghai, China), and were maintained under conditions free of specific pathogens.

Design and preparation of siRNA plasmid. For designing an siRNA targeting EphA1, the sequence AAGGAGACC TTCAACCTTCTG corresponding to nucleotides 442 to 462 of the human EphA1 mRNA (GenBank ${ }^{\mathrm{TM}}$ sequence NM 005232), was selected. Synthetic sense and antisense oligonucleotides (BoAsia, Co., Shanghai), constitute the template for generating RNA composed of two identical 19-nt sequence motifs in an inverted orientation, separated by a 9-bp spacer to form a double strand hairpin of siRNA, then annealed to generate double-stranded DNAs and ligated into the linearized empty vector pSilencer 2.1-U6 (Ambion, Austin, TX). As a negative control, a plasmid was designed to encode a hairpin RNA containing the same sequence but scrambled, as an siRNA plasmid (sequence TAACTCGACCATGAGCT GCAC. This sequence was shown by BLAST search not to share sequence homology with any known human mRNA.
Transfection. Transfection of plasmid DNAs into Huh-7 cells was done using Lipofectamine (Invitrogen). Briefly, a total of $2 \times 10^{5}$ cells were seeded into each well of a six-well tissue culture plate (Costar Corning Inc., NY). When the cells were $70-80 \%$ confluent, the cells were transfected using $2 \mu \mathrm{g}$ DNA mixed with $5 \mu \mathrm{l}$ Lipofectamine in $1 \mathrm{ml}$ medium without serum and antibiotics. The cells were incubated for $24 \mathrm{~h}$, and then $1 \mathrm{ml}$ medium containing $10 \%$ serum was added into each well. The cells were cultured and selected in medium containing $10 \%$ serum and $3 \mathrm{mg} / \mathrm{ml} \mathrm{G} 418$ (Invitrogen) for at least 3 weeks until the non-transfected Huh-7 cells cultured in the control wells were all dead. The stable transfectants, obtained by transfecting the EphA1 siRNA plasmid or scrambled plasmid into the Huh-7 cells, were designated siEphA1/Huh-7 cells and scrEphA1/Huh-7 cells, respectively.

Reverse transcriptase-polymerase chain reaction (RT-PCR) analysis. Total RNA was isolated from $10-\mathrm{cm}$ tissue culture dishes when cells were $85-95 \%$ confluent using the TRIzol Reagent (Life technologies, Inc., Frederick, MD) with slight modifications to the recommended protocol. The cDNA synthesized by reverse transcription was amplified using specific sets of primers for human EphA1 5'-GGAGGCAG ACAACAGTGTCA-3' (sense) and 5'-GAACAATGCCACC TTGGAGT-3' (antisense), for VEGF 5'-AGCTACTGCCA TCCAATCGC-3' (sense) and 5'-GGGCGAATCCAATTCC AAGAG-3' (antisense), for Angiopoietin-2 5'-GGAAGACA AGCACATCATCC-3' (sense) and 5'-AGTAAGCCTGATT CCCTTCC-3' (antisense), for MMP-2: 5'-CTCTCCTGACA TTGACCTTGGCAC-3' (sense) and 5'-AAAAACTTACTC GCTGGACATCAGGG-3' (antisense), for MMP-9: 5'-GGC ATCCGGCACCTCTATGGTCC-3' (sense) and 5'-GCCA CTTGTCGGCGATAAGGAAGG-3' (antisense), for GAPDH 5'-GTCAACGGATTTGGTCTGTATT-3' (sense) and 5'-AGTCTTCTGGGTGGCAGTGAT-3' (antisense). PCR for EphA1 was performed at $95^{\circ} \mathrm{C}$ for $30 \mathrm{sec}$, at $5^{\circ} \mathrm{C}$ for $30 \mathrm{sec}$, and at $72^{\circ} \mathrm{C}$ for $90 \mathrm{sec}$, for 27 cycles. PCR for VEGF and Angiopoietin-2 was performed at $95^{\circ} \mathrm{C}$ for $30 \mathrm{sec}$ and $68^{\circ} \mathrm{C}$ for $2 \mathrm{~min}$ for 32 cycles. PCR for MMP-2 and MMP-9 was performed at $95^{\circ} \mathrm{C}$ for $30 \mathrm{sec}$, at $58^{\circ} \mathrm{C}$ for $30 \mathrm{sec}$, and at $72^{\circ} \mathrm{C}$ for $90 \mathrm{sec}$ for 30 cycles. The PCR products were stained with SYBR-Green $\mathrm{I}^{\mathrm{M}}$ (Molecular Probes, Eugene, OR). The expression level of each gene mRNA was adjusted by the level of glyceraldehyde-3-phosphate dehydrogenase (GAPDH) mRNA and expressed as the ratio to the GAPDH mRNA.

Western blot analysis. The parental, siEphA1/Huh-7 and scrEphA1/Huh-7 cells were plated in $60-\mathrm{mm}$ dishes and allowed to adhere for $24 \mathrm{~h}$, then confluent cultures were harvested, and lysed with lysis buffer $(5 \mathrm{mmol} / 1$ EDTA; $300 \mathrm{mmol} / \mathrm{l} \mathrm{NaCl} ; 0.1 \%$ Igepal; $0.5 \mathrm{mmol} / \mathrm{l} \mathrm{NaF} ; 0.5 \mathrm{mmol} / 1$ $\mathrm{Na}_{3} \mathrm{VO}_{4} ; 0.5 \mathrm{mmol} / 1$ phenylmethylsulfonyl fluoride; and $10 \mu \mathrm{g} / \mathrm{ml}$ each of aprotinin, pepstatin, and leupeptin; Sigma, St. Louis, MO). After centrifugation at 15,000 g for $30 \mathrm{~min}$, the supernatant was analyzed for protein content using the Bradford reagent (Bio-Rad). Samples were adjusted to equal protein concentration and volume, and subjected to $8 \%$ sodium dodecyl sulfate-polyacrylamide gel electrophoresis (SDS- 
PAGE). Separate proteins were transferred to polyvinylidene difluoride (PVDF) membranes (Millipore, Bedford, MA) followed by blocking. The membranes were incubated with primary antibody against EphA1 (1:500 Santa Cruz), followed by incubation with HRP-conjugated secondary antibody (1:1000 dilution, Zymed). The specific protein was detected using a SuperSignal protein detection kit (Pierce, USA). For quantification, the bands were scanned into AlphaImager 3400 (Alpha Innotech, San Leandro, CA) and normalized by dividing the measured density of protein bands by the density of $\beta$-actin control bands from corresponding cell lysates. The protein expression of other targets was performed using the same procedures described above and the primary antibodies used were: anti-VEGF (1:500; Santa Cruz), anti-ang-2 (1:500; Santa Cruz), anti-MMP-2 (1:500; Santa Cruz), anti-MMP-9 (1:500; Santa Cruz), and anti- $\beta$-actin antibodies $(1: 1000$, Sigma).

MTT assay. Growth inhibition of siEphA1/Huh-7 cells was evaluated using a 3-[4,5-dimethylthiazol-2-yl]-2,5-diphenyltetrazolium bromide (MTT, Sigma) assay and was assessed at 24, 48 and 72 h. Briefly, Huh-7 cells, siEphA1/Huh-7 and scrEphA1/Huh-7 cells were plated in 96-well plates and grown overnight. In all $20 \mu \mathrm{l}$ MTT (5 g/l) was added into each well for $4 \mathrm{~h}$. After the medium containing MTT was absorbed, the formazan crystals were dissolved in $200 \mu \mathrm{l}$ of dimethyl sulfoxide (DMSO, Sigma). The absorbance was recorded using a Teacan 96-well spectrophotometer at wavelength of $490 \mathrm{~nm}$, with the absorbance of Huh-7 cells as the reference. The data are presented as the means $\pm \mathrm{SD}$, derived from triplicate samples of at least three independent experiments.

In vitro invasion and migration assay. Transwell filters (Costar, USA) were coated with matrigel (Becton-Dickinson, Bedford, USA; $4 \mathrm{mg} / \mathrm{ml}, 60-80 \mathrm{ml}$ ) on the upper surface of polycarbonic membrane (diameter $6.5 \mathrm{~mm}$, pore size $8 \mathrm{~mm}$ ). After incubating at $37^{\circ} \mathrm{C}$ for $30 \mathrm{~min}$, matrigel became solidified and served as the extracellular matrix for cell invasion analysis. Harvested cells $\left(1 \times 10^{5}\right)$ in $100 \mu 1$ of serum-free DMEM were added into the upper compartment of the chamber. A total of $200 \mathrm{ml}$ conditioned medium derived from $\mathrm{NIH}_{3} \mathrm{~T}_{3}$ cells was used as a source of chemoattractant and placed in the bottom compartment of the chamber. After $24 \mathrm{~h}$ of incubation at $37^{\circ} \mathrm{C}$ with $5 \% \mathrm{CO}_{2}$, the medium was removed from the upper chamber. The non-invaded cells on the upper side of the chamber were scraped off with a cotton swab. The cells that had migrated from matrigel into the pores of the inserted filter were fixed with $100 \%$ methanol, stained with crystal violet, mounted and dried at $80^{\circ} \mathrm{C}$ for $30 \mathrm{~min}$. The number of cells invading through the matrigel was counted using three randomly selected visual fields from the central and peripheral portion of the filter by an inverted microscope at x200 magnification.

In a similar fashion, the migration assay of $\mathrm{SiEphA1/}$ Huh-7 cells was evaluated on coated 24-well transwell chambers with Matrigel ${ }^{\mathrm{TM}}$. ScrEphA1/Huh-7 cells and Huh-7 cells were used as controls. Cells, media, experimental conditions and analysis performed were similar to those of invasion assays. Triplicate assays were performed for each group of cells in both invasion and migration assays and results are expressed as means \pm SD.

Subcutaneous tumor xenograft model. All protocols involving animals were reviewed and approved by the Ethics Review Committee of Wenzhou Medical College. Six to eight-week old male BALB/c nude mice were used for for growth of subcutaneous tumors. Cells $\left(10^{7}\right)$ were injected in the flank of a mouse in a serum-free medium mixed with an equal volume of Matrigel. After 28 days, the xenograft was removed, cut into slices with the same volume, and then implanted into the right flank of three experimental groups of six animals per group. The tumors were removed on day 35 . Tumor size was measured twice weekly with calipers. Volumes of tumors were determined using the formula, volume $=$ width $^{2} \times$ length $\times 0.52$. Harvested tissues were fixed in $10 \%$ buffered formalin, and embedded in paraffin for further analysis.

Evaluation of microvessel density. Microvessel density (MVD) of the tumours was evaluated simultaneously by two independent observers according to the methods described by Weidner et al (28). Briefly, after immunostaining with anti-CD34 monoclonal antibody (diluted 1:50; Dako), the tumors were first screened at a low power (x40) to identify areas of the highest MVD. Counts were taken in the 5 highest MVD areas at a high power (x200, $0.74 \mathrm{~mm}^{2}$ per field). Microvessels that stained positively with anti-CD34 antibody, were counted in 5 microscopic fields of the neovascularization with the highest density. The mean value of the fields counted by each observer was considered the MVD of an individual tumor.

Statistical analysis. A commercially available software package SPSS12.0 was used for statistical analysis. Oneway analysis of variance (ANOVA) and $\chi^{2}$ best was used to analysis the significance between groups. The LSD method of multiple comparisons with parental and control groups was used when the probability for ANOVA was statistically significant. Statistical significance was determined at the level of $\mathrm{p}<0.05$.

\section{Results}

Suppression of EphAl expression by siRNA. Huh-7 human hepatocellular carcinoma cells are normally constitutively expressing EphA1 at high levels (25). We specifically suppressed EphA1 expression in Huh-7 cells by RNAi technology. Huh-7 cells were transfected with the constructed plasmid encoding siRNA targeting to EphA1 and with a negative control plasmid containing a random scrambled sequence, respectively. The stable transfectants with EphA1 siRNA (SiEphA1/Huh-7) and scrambled random sequence siRNA (ScrEphA1/Huh-7) were established by G418 selection. To examine the efficiency for silencing EphA1, we detected the level of mRNA expression in the transfectants (Fig. 1A). The reverse transcription PCR (RT-PCR) data showed that the level of EphA1 mRNA was significantly decreased in SiEphA1/Huh-7 cells as compared with Huh-7 cells $(\mathrm{P}<0.01)$, while there was no difference between the 


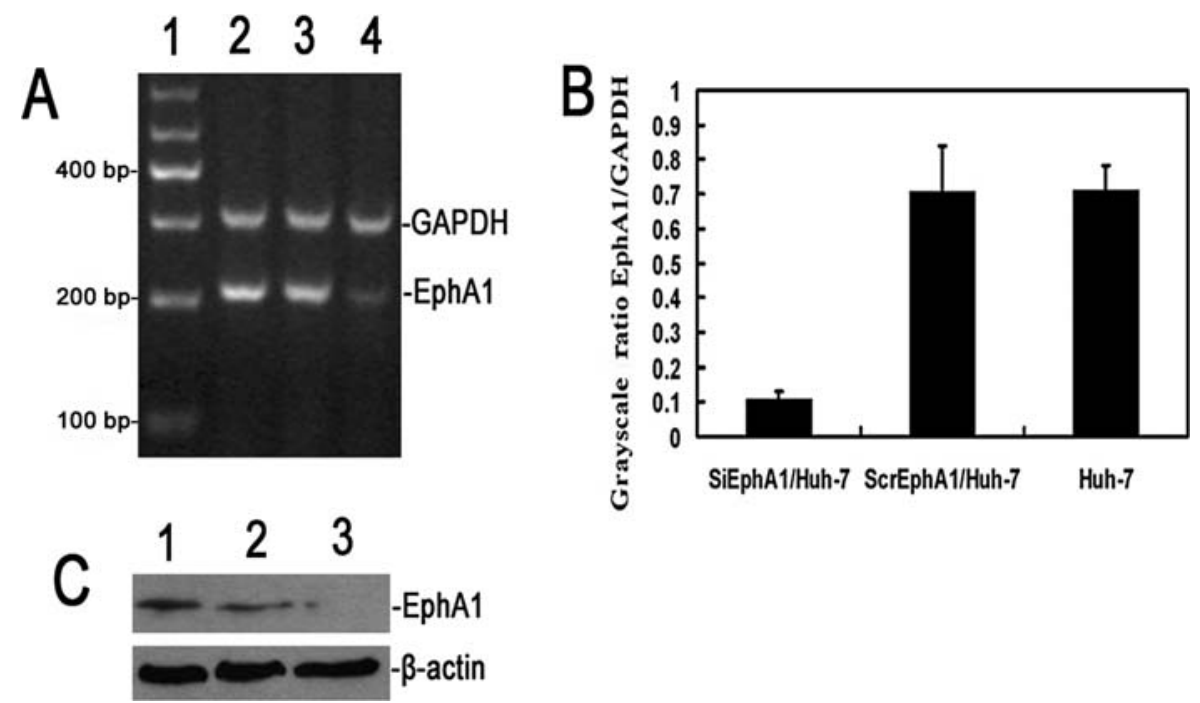

Figure 1. Semi-quantitiative reverse transcription-PCR and Western blotting of EphA1. (A) Reverse transcription-PCR products of total RNA in three samples of Huh-7 cells, electrophoresed on 1.5\% agarose gels as described in Materials and methods. Lane 1, marker; lane 2, Huh-7 cells; lane 3, ScrEphA1/Huh-7 cells; lane 4, siEphA1/Huh-7 cells. (B) Comparison of grayscale ratio of EphA1/GAPDH in SiEphA1/Huh-7, ScrEphA1/Huh-7 and Huh-7 cells. (C) Western blot analysis of EphA1 protein level in three different Huh-7 samples: lane 1, Huh-7 cells; lane 2, ScrEphA1/Huh-7 cells; lane 3, SiEphA1/Huh-7 cells.
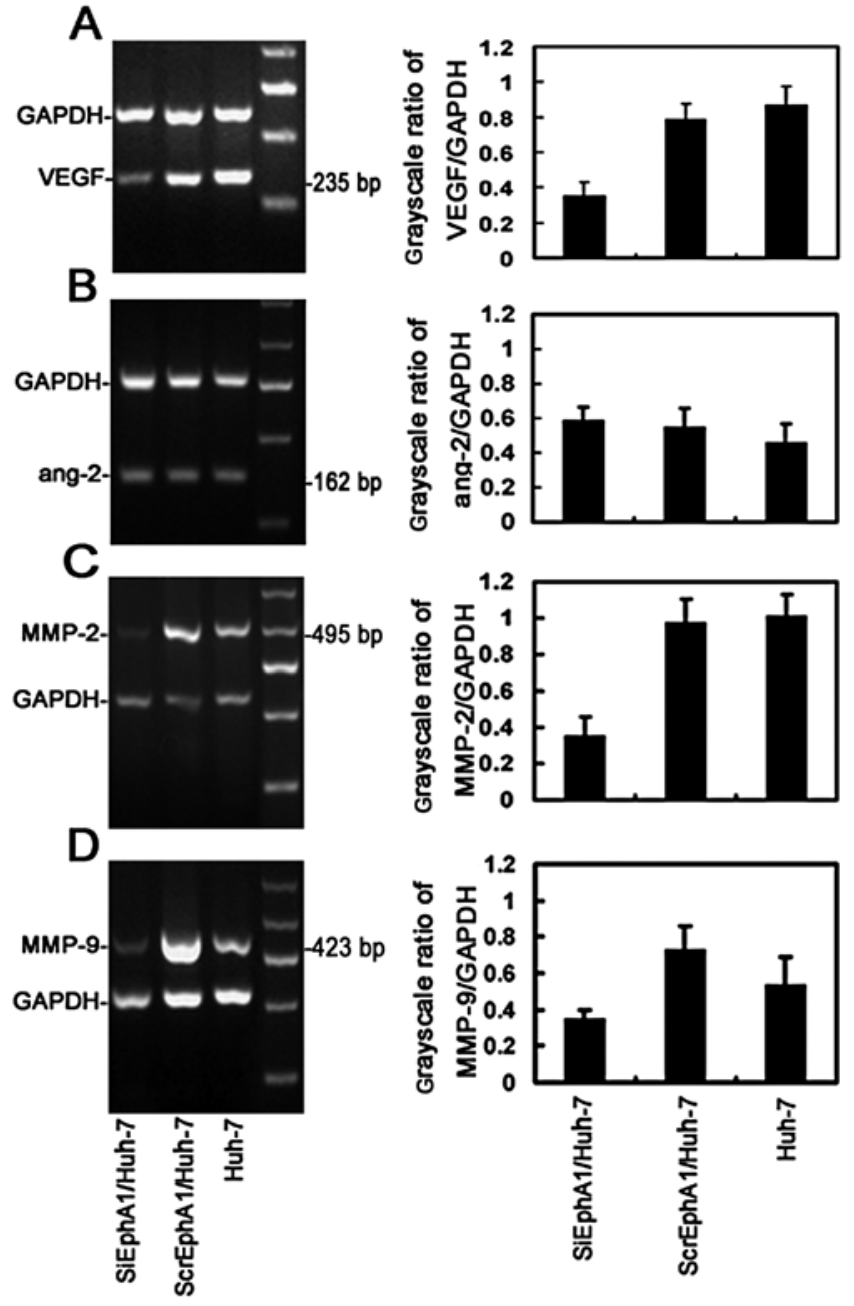

Figure 2. RT-PCR detection of VEGF, ang-2, MMP-2, MMP-9 mRNA (A-D, respectively) in Huh-7 and transfected cells (siEphA1/Huh-7 and scrEphA1/Huh-7). The amounts of VEGF, Ang-2, MMP-2, MMP-9 RT-PCR products $(235,162,495,423 \mathrm{bp}$, respectively) were evaluated using a digital image analysis system (IAS). Right panels show mean values of three different experiments $\pm \mathrm{SD}$.
ScrEphA1/Huh-7 cells and Huh-7 cells ( $\mathrm{P}>0.05$, Fig. 1B). Furthermore, Western blot analysis was used to confirm the result of RT-PCR. The quantitative analysis of EphA1 protein showed that the expression level of protein of EphA1 in SiEphA1/Huh-7 cells was decreased by $76 \%$, whereas the negative control plasmid did not affect the expression of EphA1 protein (Fig. 1C).

Suppression of EphAl induces inhibition of VEGF, MMP-2 and MMP-9 expression. EphA1, VEGF and Angiopoietin-2 are all members of the endothelial cell receptor tyrosine kinase (RTK) family, which have been recognized as critical mediators of tumor angiogenesis. The functions of VEGF and Angiopoietin-2 and their reciprocity in HCC are well studied (39). We tested the mRNA and protein level of VEGF and Angiopoietin-2 in Huh-7 cells with normal and suppressed expression of EphA1. The results show that knockdown of EphA1 results in suppression of VEGF mRNA $(\mathrm{P}<0.01)$, whereas the scrambled siRNA did not $(\mathrm{P}>0.05$, Fig. 2A). The expression of Ang-2 mRNA in SiEphA1/Huh-7 cells was not significantly different from that in Huh-7 cells and ScrEphA1/ Huh-7 cells $(\mathrm{P}>0.05)$ (Fig. 2B). Similar results were found at the protein level. Western blot analysis showed a significant down-regulation of VEGF in SiEphA1/Huh-7 cells by $35 \%$ $(\mathrm{P}<0.01$, Fig. 3A). Ang-2 was not found to be regulated (Fig. 3B).

In addition, we evaluated the protein expression of several metastasis indicators which have been previously shown to be associated with Eph receptors in several tumor types. RT-PCR results show a 55 and $42 \%$ decrease in MMP-2 and MMP-9, respectively, in SiEphA1/Huh-7 cells $(\mathrm{P}<0.01)$. Protein data paralleled these findings (62 and $48 \%$, respectively, $\mathrm{P}<0.01)$.

Down-regulation of EphAl in Huh-7 cells inhibits invasion and migration in vitro. We evaluated whether downregulation of EphA1 expression would alter the ability 

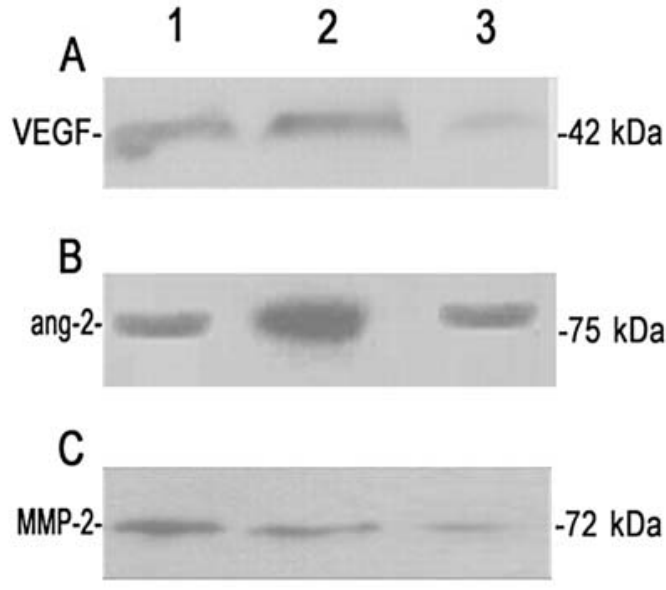

D

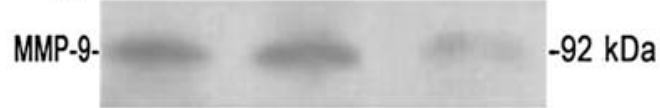

$\mathrm{E}$

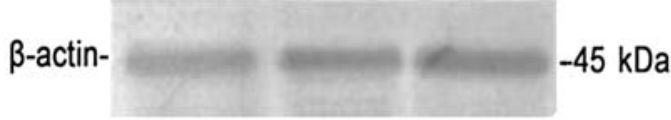

Figure 3. Western blot analysis of VEGF, Ang-2, MMP-2, MMP-9 and B-actin protein amount (A-E, respectively) in Huh-7 and transfected cells (siEphA1/Huh-7 and scrEphA1/Huh-7) using anti-VEGF, anti-Ang-2, antiMMP-2, anti-MMP-9 and anti- 3 -actin antibodies as described in Materials and methods. Lane 1, Huh-7 cells; lane 2, ScrEphA1/Huh-7 cells; lane 3, siEphA1/Huh-7 cells.

of Huh-7 cells to invade into Matrigel, a solubilized seminatural basement membrane preparation extracted from the EHS mouse sarcoma. The invasiveness of SiEphA1/Huh-7 cells was assessed using Matrigel coated transwell invasion chambers as described in Materials and methods. The 24-h invasion by $\mathrm{SiEphA1/Huh-7} \mathrm{cells} \mathrm{was} \mathrm{inhibited} \mathrm{to} 78 \%$ of the level of Huh-7 cells $(\mathrm{P}<0.05$, Fig. $4 \mathrm{~A})$. Invasion of ScrEphA1/Huh-7 cells was similar $(103 \%)$ to the parental Huh-7 cells. Parallel experiments were performed in triplicate and membranes used for the invasion assays were stained with $0.2 \%$ crystal violet and mounted on glass microscope slides. Representative sections are shown at x200 magnification (Fig. 4).

To study the effect of siRNA EphA1 transfection on migratory capacity of the cells, parental and transfected cells were seeded on transwell chambers with uncoated filters. After $24 \mathrm{~h}$ of incubation, the motility potential of SiEphA1/ Huh-7 cells was found to be strongly inhibited (Fig. 4B; $\mathrm{P}<0.05)$. Parallel experiments were performed in triplicate and membranes used for the migration assays were prepared, as described above and shown in Fig. 4B.

Cell proliferation assay. We subsequently determined the proliferation of SiEphA1/Huh-7 cells, ScrEphA1/Huh-7 and parent Huh-7 cells. As shown in Fig. 5, while there was no difference in proliferation between all different cells at 24 and $48 \mathrm{~h}(\mathrm{P}>0.05)$, there was a significant inhibition in SiEphA1/ Huh-7 cells after $72 \mathrm{~h}$ to $75.8 \%$ of control $(\mathrm{P}<0.01)$. There
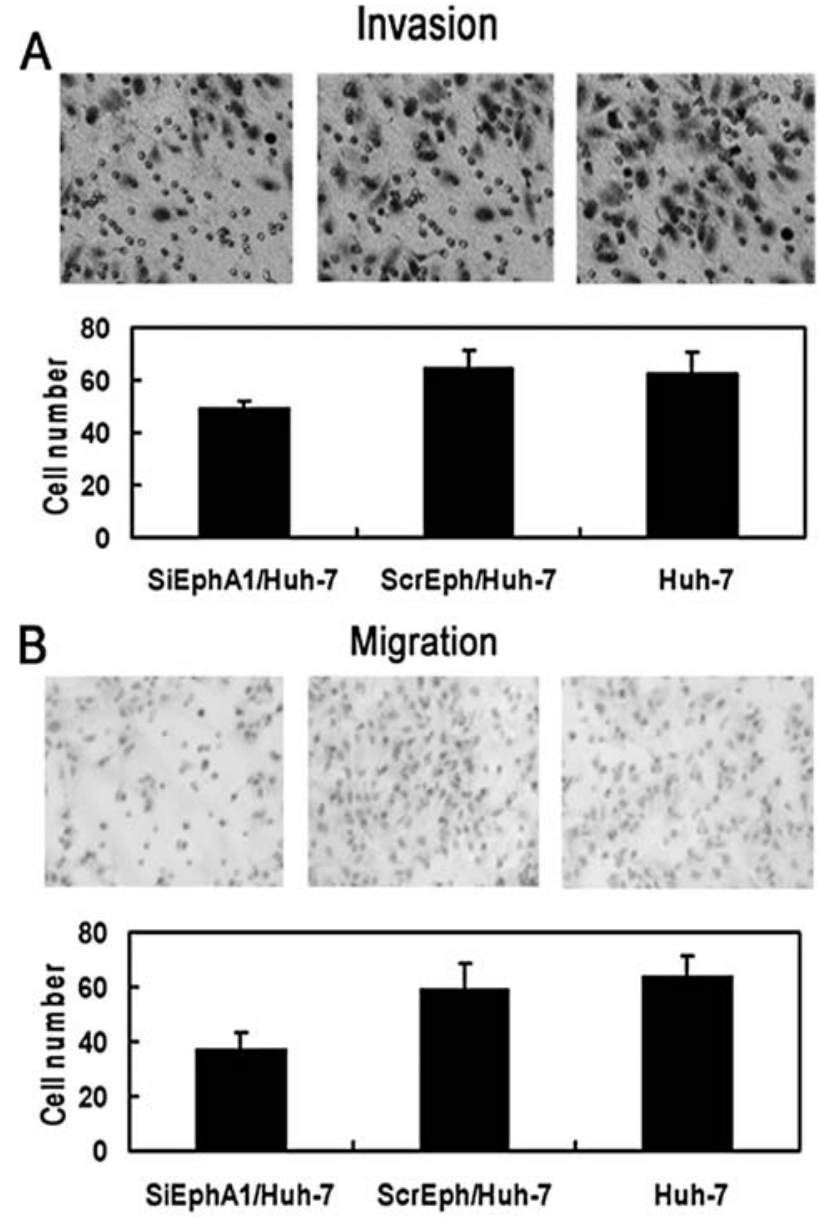

Figure 4. Invasion (A) and motility (B) of siEphA1/Huh-7 cells, scrEphA1/ Huh-7 cells and Huh-7 cells. The percentage of invading $(\mathrm{t}=24 \mathrm{~h})$ and migrating $(\mathrm{t}=24 \mathrm{~h})$ cells was calculated as reported in Material and methods. The picture highlights the differences in number between the siEphA1/ Huh-7 cells, scrEphA1/Huh-7 cells and Huh-7 cells able to invade (A) or migrate (B) to the lower surface of transwell system. The cells were stained with crystal violet. Bars represent mean values of three different experiments $\pm \mathrm{SD}$.

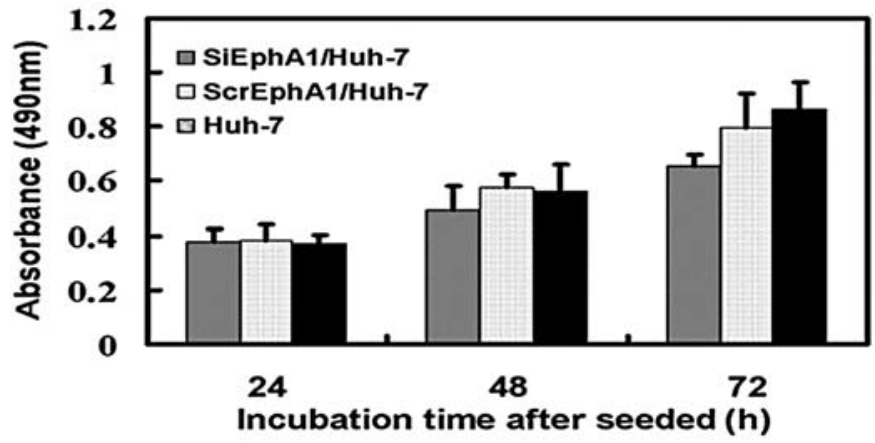

Figure 5. Decrease in the proliferation potential of cells transfected with EphA1-targeting siRNA. SiEphA1/Huh-7, ScrEphA1/Huh-7 and Huh-7 cells seeded in 96-well microplates were cultured for 24, 48 and $72 \mathrm{~h}$ and their number was determined by absorbance. At $72 \mathrm{~h}$ the proliferation of SiEphA1/Huh-7 cells was significantly inhibited compared with ScrEphA1/Huh-7 cells $(\mathrm{P}<0.05)$ and Huh-7 cells $(\mathrm{P}<0.01)$.

was no significant difference between ScrEphA1/Huh-7 cells and Huh-7 cells throughout all experiments. 

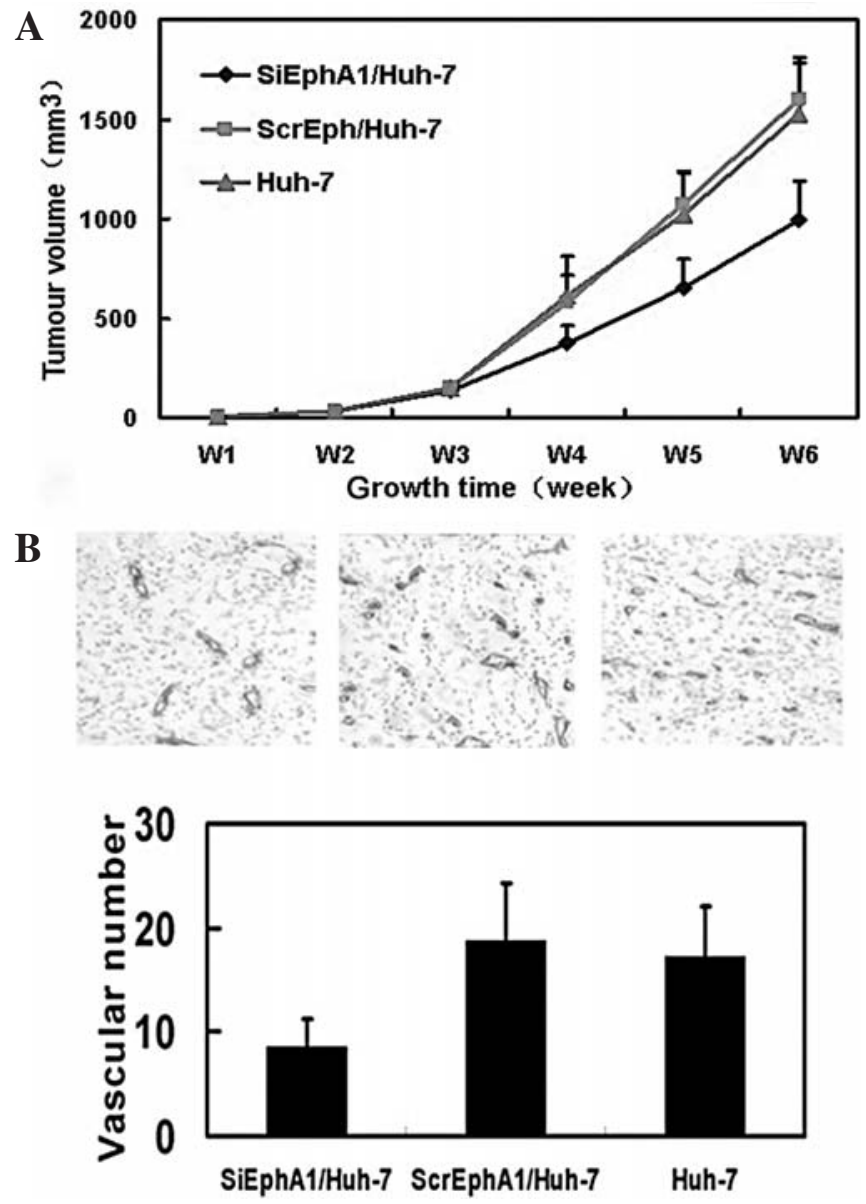

Figure 6. Effects of EphA1 knockdown on tumor growth and microvessel density, in vivo. (A) Growth curves of transplanted tumors in nude mice. Melanoma cells were injected s.c. into the right flank and the size and volume of the transplanted tumors were measured $(n=6)$. (B) Immunohistochemical analysis of CD34-positive microvessels in transplanted tumors The picture highlights the differences in MVD between the siEphA1/Huh-7 cells, scrEphA1/Huh-7 cells and Huh-7 cell xenografts.

Growth retardation of the Huh-7 cell xenografts by knockdown of EphA1. The in vitro experiments have demonstrated that silencing EphA1 expression can efficiently inhibit Huh7 cell proliferation, and down-regulate motility and invasion of Huh-7 cells. Therefore, we further investigated the effects of EphA1 knockdown by siRNA technology on tumor growth in vivo. To that end we used nude mice and injected the Huh-7 variants subcutaneously for growth of xenograft tumors. All mice were monitored every 7 days for 5 weeks, and the tumor volumes were measured and compared. At day 35 , the mean tumor volumes of the different groups was $994 \pm 198,1599 \pm 209,1526 \pm 256 \mathrm{~mm}^{3}$, respectively for SiEphA1/Huh-7, ScrEphA1/Huh-7 and Huh-7 cells. This indicates a signi-ficant tumor growth inhibition by knockdown of EphA1 ( $\mathrm{P}>0.05$, Fig. 6A).

To assess the microvessel density, tumor sections were immunostained with antibody against the endothelial cellspecific marker CD34 (Fig. 6B). Quantification of CD34 staining revealed a significantly decreased microvessel density in SiEphA1/Huh-7 xenografts as compared with ScrEphA1/ Huh-7 cells xenografts $(\mathrm{P}<0.01)$ and Huh-7 cell xenografts $(\mathrm{P}<0.05)$. Thus, EphA1 RNAi significantly suppressed tumor growth and MVD in nude mice in comparison with control, indicating that targeting EphA1 by RNAi can exert a strong antitumor and antiangiogenesis effect in vivo.

\section{Discussion}

Accumulating evidence demonstrates that an elevated expression of Eph receptors is positively correlated with the growth of solid tumors. However, the function of this family of receptor tyrosine kinases in carcinogenesis and tumor angiogenesis has just begun to be investigated. Recent studies have indicated that overexpression of the EphA1 receptor was found in $\mathrm{HCC}$, but reports characterizing the role and mechanism of EphA1 in progression and tumor angiogenesis of HCC are still lacking. In this study, we suppressed EphA1 expression in Huh-7 hepatocellular carcinoma cell lines (SiEphA1/ Huh-7 cells), and we found that this attenuation of EphA1 expression is associated with a decline in cell proliferation $(\mathrm{P}<0.05)$, cell motility $(\mathrm{P}<0.05)$ and cell invasiveness $(\mathrm{P}<0.05)$. In vivo, we found that tumor growth of SiEphA1/Huh-7 cells was significant retarded relative to ScrEphA1/Huh-7 $(\mathrm{P}<0.01)$ and Huh-7 cells $(\mathrm{P}<0.01)$. In addition, the microvessel density in SiEphA1/Huh-7 tumors was lower than in ScrEphA1/Huh-7 $(\mathrm{P}<0.05)$ and Huh-7 tumors $(\mathrm{P}<0.05)$. In addition, we found that silenced EphA1 expression was associated with reduced expression of VEGF protein, but not Ang-2 protein. We also found reduced expression of MMP-2 and MMP-9 in SiEphA1/Huh-7 tumors.

In gene function studies, the specific knockdown of target genes without affecting other genes is critically important. RNAi mediated by siRNA and shRNA is a specific genesilencing technology. We used this technology to construct the EphA1 siRNA expression vector pSilencer 2.1-U6/ EphA1siRNA for transfection into the Huh-7 hepatocellular carcinoma cell line. We established two stably transfected cells, the SiEphA1/Huh-7 and ScrEphA1/Huh-7 cell lines. SiEphA1/Huh-7 cells significantly reduced EphA1 mRNA expression, whereas ScrEphA1/Huh-7 did not. We postulate that positional effects $(29,30)$ and variance in the secondary structure of the nucleotide sequence at different sites $(31,32)$ played a role in the different inhibitory effects of the siRNA targeting the same gene. To test the silence effect of EphA1 expression, we used RT-PCR and Western blotting methods. The results showed the pSilencer 2.1-U6/ EphA1siRNA can inhibit EphA1 protein $(76 \%)$ and mRNA (85\%) expression in Huh-7 cells.

It is now widely recognised that angiogenesis plays a pivotal role in the development of solid tumors, including HCC $(33,34)$. Endothelial cell receptor tyrosine kinases (RTK), which include VEGF receptors, Tie receptors and ephrins/Eph receptors, have been recognized as critical mediators of angiogenesis. It has been reported that VEGF and Ang-2 were highly expressed in HCC, and overexpression of VEGF and Ang-2 significantly enhanced HCC tumor development and angiogenesis (35-37). Recent studies showed that EphA1 and its ligand ephrin-A1 are overexpressed in HCC tumors and cell lines, but their functions in carcinogenesis and angiogenesis of HCC are unknown. Tumor angiogenesis requires high a degree of cooperation between various cell types and several angiogenic factors involved. 
The cooperation of angiogenic factors has been reported in previous studies. Yoshiji et al reported that VEGF and basic fibroblast growth factor (bFGF) showed a synergistic effect on HCC development and angiogenesis (38). They also revealed that VEGF and Ang-2 have a synergistic effect on HCC development and angiogenesis, and Ang-2 plus VEGF induced tumor development was markedly attenuated by treatment with neutralising monoclonal antibodies against VEGF receptors (39). In addition, Chen et al indicated that blockade of EphA-class receptor activation can inhibit several VEGF-mediated angiogenic processes, including migration, assembly, sprouting, survival, and corneal/retinal angiogenesis $(40,41)$. In this study, we found that restraining the expression of EphA1 receptor can dramatically decrease the expression of VEGF mRNA and protein, but no obviously influence was found in the expression of Ang-2 mRNA and protein. Our research demonstrated that the role of EphA1 in HCC concerns VEGF but not Ang-2.

A good correlation has been found between the expression of MMPs and the invasive ability of malignant tumors, including HCC $(42,43)$. Among the MMPs, MMP-2 and MMP-9 are reported to be overexpressed in HCC $(44,45)$. Furthermore, in a previous study, Mayoral et al confirmed that MMP-2 and MMP-9 were up-regulated in Huh-7 cells, and their higher expression was correlated with cell migration (46). The relationship between MMPs and other angiogenic factors in tumor development and angiogenesis have been well studied. MMP-9 was found to be up-regulated by Ang-2 in the presence of VEGF, whereas Ang-2 alone did not show such an effect in endothelial cells in vitro (47). Moreover, MMP-9 has been shown to be a trigger of the angiogenic switch during carcinogenesis, and a synthetic inhibitor of VEGF signalling impaired this angiogenic switch as well as tumor growth (48). In another study, significant upregulation of MMP-2 was found in the Ang-2 plus VEGF overexpressing tumour and induction of MMP-2 and MMP-9 by Ang-2 plus VEGF may also contribute to HCC development and angiogenesis (39). We used RNAi technology to down-regulated the EphA1 expression in Huh-7 cells, and subsequently assessed MMP-2 and MMP-9 expression. The result showed that mRNA and protein expression of these two genes were both decreased. Combined with the results that down-regulation of EphA1 expression in Huh-7 cells can effectually weaken the invasive and motility ability, we presumed that the invasion and motility in HCC involve MMP-2 and MMP-9 function.

In our study, we have shown that inhibition of endogenous EphA1 using siRNA techniques reduced the proliferation of HCC cells. This was correlated to the retardation of the growth of SiEphA1/Huh-7 cell xenografts. Previous research have indicated that inhibiting the activity of EphA receptor can inhibited tumor angiogenesis and tumor growth in vivo, and this inhibition of tumor growth correlated with decreased vascular density and tumor cell proliferation (18). Similarly, we found that microvessel density (MVD) of xenografts was significantly reduced in SiEphA1/Huh-7 tumors as compared to ScrEphA1/Huh-7 and Huh-7 based tumors. One of the strongest stimulatory angiogenic factors, VEGF overexpression in the HCC xenograft model, resulted in increased neovascularization and tumor size (35). Taken together, our study presents the role of EphA1 in tumor growth and angiogenesis, and its contribution is suggested to involve VEGF.

\section{Acknowledgements}

We acknowledge Dr Wenzhuang Sheng, at the Department of General Surgery, Tongji Hospital, Tongji Medical College, Huazhong University of Science and Technology, Wuhan, China, for editorial assistance with this article.

\section{References}

1. Parkin DM, Bray F, Ferlay J and Pisani P: Estimating the world cancer burden: Globocan 2000. Int J Cancer 94: 153-156, 2001.

2. Poon RT, Ng IO, Lau C, et al: Tumor microvessel density as a predictor of recurrence after resection of hepatocellular carcinoma: a prospective study. J Clin Oncol 20: 1775-1785, 2002.

3. Tanigawa N, Lu C, Mitsui T and Miura S: Quantitation of sinusoid-like vessels in hepatocellular carcinoma: its clinical and prognostic significance. Hepatology 26: 1216-1223, 1997.

4. Sugimachi K, Tanaka S, Terashi T, Taguchi K, Rikimaru T and Sugimachi K: The mechanisms of angiogenesis in hepatocellular carcinoma:angiogenic switch during tumor progression. Surgery 131 (Suppl): S135-S141, 2002.

5. Yancopoulos G, Davis S, Gale NW, Rudge JS, Weigand SJ and Holash J: Vascular-specific growth factors and blood vessel formation. Nature 407: 242-248, 2000.

6. Flanagan JG and Vanderhaeghen P: The ephrins and Eph receptors in neural development. Annu Rev Neurosci 21: 309345, 1998.

7. Zelinski DP, Zantek ND, Stewart JC, Irizarry AR and Kinch MS: EphA2 over-expression causes tumorigenesis of mammary epithelial cells. Cancer Res 61: 2301-2306, 2001.

8. Walker-Daniels J, Coffman K, Azimi M, et al: Overexpression of the EphA2 tyrosine kinase in prostate cancer. Prostate 41: 275-280, 1999.

9. Kinch MS, Moore MB and Harpole DH: Predictive value of the EphA2 receptor tyrosine kinase in lung cancer recurrence and survival. Clin Cancer Res 9: 613-618, 2003.

10. Shao Z, Zhang WF, Chen XM and Shang ZJ: Expression of EphA2 and VEGF in squamous cell carcinoma of the tongue: correlation with the angiogenesis and clinical outcome. Oral Oncol 44: 1110-1117, 2008

11. Oshima T, Akaike M, Yoshihara K, et al: Overexpression of EphA4 gene and reduced expression of EphB2 gene correlates with liver metastasis in colorectal cancer. Int J Oncol 133: 573-577, 2008.

12. Nakamura R, Kataoka H, Sato N, et al: EPHA2/EFNA1 expression in human gastric cancer. Cancer Sci 96: 42-47, 2005.

13. Nemoto T, Ohashi K, Akashi T, Johnson JD and Hirokawa K: Overexpression of protein tyrosine kinases in human esophageal cancer. Pathobiology 65: 195-203, 1997.

14. Easty DJ, Hill SP, Hsu MY, et al: Up-regulation of ephrin-A1 during melanoma progression. Int J Cancer 84: 494-501, 1999.

15. Wu D, Suo Z, Kristensen GB, et al: Prognostic value of EphA2 and Ephrin-A1 in squamous cell cervical carcinoma. Gynecol Oncol 94: 312-319, 2004.

16. Alam SM, Fujimoto J, Jahan I, Sato E and Tamaya T: Coexpression of EphB4 and ephrinB2 in tumour advancement of ovarian cancers. Br J Cancer 98: 845-851, 2008.

17. Nasreen N, Mohammed KA, Lai Y and Antony VB: Receptor EphA2 activation with ephrinA1 suppresses growth of malignant mesothelioma (MM). Cancer Lett 258: 215-222, 2007.

18. Dobrzanski P, Hunter K, Jones-Bolin S, et al: Antiangiogenic and antitumor efficacy of EphA2 receptor antagonist. Cancer Res 64: 910-919, 2004.

19. Brantley DM, Cheng N, Thompson EJ, et al: Soluble Eph A receptors inhibit tumor angiogenesis and progression in vivo. Oncogene 21: 7011-7026, 2002. 
20. Brantley-Sieders DM, Fang WB, Hwang Y, Hicks D and Chen J: Ephrin-A1 facilitates mammary tumor metastasis through an angiogenesis-dependent mechanism mediated by EphA receptor and vascular endothelial growth factor in mice. Cancer Res 66: 10315-10324, 2006.

21. Hirai H, Maru Y, Hagiwara K, Nishida J and Takaku F: A novel putative tyrosine kinase receptor encoded by the eph gene. Science 238: 1717-1720, 1987.

22. Robinson D, He F, Pretlow T and Kung HJ: A tyrosine kinase profile of prostate carcinoma. Proc Natl Acad Sci USA 93: 5958-5962, 1996.

23. Kao HW, Chen $\mathrm{HC}, \mathrm{Wu} \mathrm{CW}$ and Lin WC: Tyrosine-kinase expression profiles in human gastric cancer cell lines and their modulations with retinoic acids. Br J Cancer 88: 1058-1064, 2003.

24. Maru Y, Hirai H, Yoshida MC and Takaku F: Evolution, expression and chromosomal location of a novel receptor tyrosine kinase gene, eph. Mol Cell Biol 8: 3770-3776, 1998.

25. Iida $\mathrm{H}$, Honda $\mathrm{M}$, Kawai HF, et al: Ephrin-A1 expression contributes to the malignant characteristics of $\alpha$-fetoprotein producing hepatocellular carcinoma. GUT 53: 843-851, 2005.

26. Maru Y, Hirai H and Takaku F: Overexpression confers an oncogenic potential upon the eph gene. Oncogene 5: 445-447, 1990 .

27. Brantley-Sieders D, Schmidt S, Parker M and Chen J: Eph receptor tyrosine kinases in tumor and tumor microenvironment. Curr Pharm Des 27: 3431-3442, 2004.

28. Weidner N, Semple JP, Welch WR and Folkman J: Tumor angiogenesis and metastasis correlation in invasive breast carcinoma. N Engl J Med 324: 1-8, 1991.

29. Brummelkamp TR, Bernards R and Agami R: A system for stable expression of short interfering RNAs in mammalian cells. Science 296: 550-553, 2002

30. Holen T, Amarzguioui M, Wiiger MT, Babaie E and Prydz H: Positional effects of short interfering RNAs targeting the human coagulation trigger tissue factor. Nucleic Acids Res 30: 1757-1766, 2002

31. Elbashir SM, Harborth J, Lendeckel W, Yalcin A, Weber K and Tuschl T: Duplexes of 21-nucleotide RNAs mediate RNA interference in cultured mammalian cells. Nature 411: 494-498, 2001.

32. Elbashir SM, Lendeckel W and Tuschl T: RNA interference is mediated by 21-and 22-nucleotide RNAs. Genes Dev 15: 188-200, 2001.

33. Kerbel RS: Tumor angiogenesis: past, present and the near future. Carcinogenesis 21: 505-515, 2000.

34. Carmeliet P: Angiogenesis in health and disease. Nat Med 9 653-660, 2003.

35. Yoshiji H, Kuriyama S, Yoshii J, et al: Vascular endothelial growth factor tightly regulates in vivo development of murine hepatocellular carcinoma cells. Hepatology 28: 1489-1496, 1998.
36. Tait CR and Jones PF: Angiopoietins in tumors: the angiogenic switch. J Pathol 204: 1-10, 2004

37. Tanaka S, Mori M, Sakamoto Y, Makuuchi M, Sugimachi K and Wands JR: Biologic significance of angiopoietin-2 expression in human hepatocellular carcinoma. J Clin Invest 103: 341-345, 1999.

38. Yoshiji H, Kuriyama S, Yoshii J, et al: Synergistic effect of basic fibroblast growth factor and vascular endothelial growth factor in murine hepatocellular carcinoma. Hepatology 35: 834-842, 2002.

39. Yoshiji H, Kuriyama S, Noguchi R, et al: Angiopoietin 2 displays a vascular endothelial growth factor dependent synergistic effect in hepatocellular carcinoma development in mice. Gut 54: $1768-1775,2005$

40. Cheng N, Brantley DM, Liu H, et al: Blockade of EphA receptor tyrosine kinase activation inhibits vascular endothelial cell growth factor-induced angiogenesis. Mol Cancer Res 1: 2-11, 2002.

41. Chen J, Hicks D, Brantley-Sieders D, et al: Inhibition of retinal neovascularization by soluble EphA2 receptor. Exp Eye Res 82: 664-673, 2006

42. Kuyvenhoven JP, van Hoek B, Blom E, et al: Assessment of the clinical significance of serum matrix metalloproteinases MMP-2 and MMP-9 in patients with various chronic liver diseases and hepatocellular carcinoma. Thromb Haemost 89: 718-725, 2003.

43. Giannelli G, Bergamini C, Marinosci F, et al: Clinical role of MMP-2/TIMP-2 imbalance in hepatocellular carcinoma. Int J Cancer 97: 425-431, 2002.

44. Määttä M, Soini Y, Liakka A and Autio-Harmainen H: Differential expression of matrix metalloproteinase (MMP)-2, MMP-9, and membrane type 1-MMP in hepatocellular and pancreatic adenocarcinoma: implications for tumor progression and clinical prognosis. Clin Cancer Res 6: 2726-2734, 2000.

45. Arii S, Mise M, Harada T, et al: Overexpression of matrix metalloproteinase 9 gene in hepatocellular carcinoma with invasive potential. Hepatology 24: 316-322, 1996.

46. Mayoral R, Fernández-Martínez A, Boscá L and Martín-Sanz P: Prostaglandin E2 promotes migration and adhesion in hepatocellular carcinoma cells. Carcinogenesis 26: 753-761, 2005.

47. Etoh T, Inoue H, Tanaka S, Barnard GF, Kitano S and Mori M: Angiopoietin-2 is related to tumor angiogenesis in gastric carcinoma: possible in vivo regulation via induction of proteases. Cancer Res 61: 2145-2153, 2001.

48. Bergers G, Brekken R, McMahon G, et al: Matrix metalloproteinase-9 triggers the angiogenic switch during carcinogenesis. Nat Cell Biol 2: 737-744, 2000. 